\title{
Evaluating Various Low-Impact Development Scenarios for Optimal Design Criteria Development
}

\author{
Mijin Seo ${ }^{1}$, Fouad Jaber ${ }^{2, *}$ and Raghavan Srinivasan ${ }^{3}$ \\ 1 National Institute of Agricultural Sciences, Rural Development Administration, Wanju, \\ Jeollabuk-do 565-851, Korea; mjseo1020@korea.kr \\ 2 Biological and Agricultural Engineering, Texas A\&M AgriLife Extension, Dallas, TX 75252, USA \\ 3 Spatial Science Laboratory, Texas A\&M University, College Station, TX 77845, USA; r-srinivasan@tamu.edu \\ * Correspondence: f-jaber@tamu.edu; Tel.: +1-972-952-9672
}

Academic Editors: Karim Abbaspour, Saeid Ashraf Vaghefi, Monireh Faramarzi and Lei Chen Received: 29 December 2016; Accepted: 9 April 2017; Published: 12 April 2017

\begin{abstract}
Low-impact development (LID) practices as a new approach to urban stormwater management have demonstrated their positive effects through the reduction of surface runoff volumes and pollutant loadings in a substantial amount of research. The effectiveness of LID practices can be affected by various LID conditions such as type, location, and area. Cost is also an important factor to be considered in the evaluation of LID effects. This study presented the optimal LID conditions that can achieve targeted reduction goals with minimal cost, and analyzed the effectiveness of LID practices under optimal LID conditions and the consequential cost on a watershed scale. To determine cost-effective LID conditions, three types of LID practices (rain gardens, rainwater harvesting tanks, and permeable pavements), two locations (residential and commercial areas), and percent allocation of LID practices were considered. Manual optimization was conducted under those LID conditions for five targeted reduction goals which were set for surface runoff and nutrient loadings. The results provided various configurations of cost-effective conditions in treating the targeted goals, and represented the impacts of the optimized LID conditions on the effectiveness of LID practices and the consequential cost. The present study could ultimately assist regulators in establishing proper watershed-scale strategies of LID conditions for effectively managing watersheds.
\end{abstract}

Keywords: low-impact development (LID) conditions; effectiveness of LID practices; manual optimization; cost; watershed management

\section{Introduction}

Development increases impervious land cover [1]. Urban impervious surfaces have aggregated stormwater problems. Specifically, surface runoff volume is significantly increased as infiltration is hindered. This decreases groundwater recharge and accordingly reduces the amount of base flow [2]. Significant water-bound pollutants are conveyed to nearby water bodies by the increased urban runoff flowing over the impervious surfaces [3]. It is necessary to take corrective action in response to these stormwater problems. Installation of low-impact development (LID) practices is one method to offset the adverse impact caused by urbanization. LID practices help to achieve both development and environmental protection by imitating the hydrology of a pre-developed state. Research on the effects of LID practices has been active and has comprehensively been addressed in a variety of studies. Most studies have demonstrated the benefits of LID practices by showing an increase of recharge rate [4] and reductions in runoff volume and pollutant loadings [5-8].

However, the degree of the effectiveness of LID practices can be affected by various factors. Some studies, for example, have reported the different effects of LID practices on water quantity and quality under different types of soil $[9,10]$ and under various rainfall patterns [11-13]. A few 
studies have pointed out that different effects of LID practices could exist depending on how urban areas are designed $[9,14,15]$. Seo et al. [16] also evaluated the effectiveness of LID practices on hydrology and water quality under three land uses with different types of urban patterns (compact high-density, conventional medium-density, and conservational medium-density) using the Soil and Water Assessment Tool (SWAT) and presented the optimal land use.

In addition to these external conditions, the effectiveness of LID practices can also be expected to vary as a result of various LID planning and design factors such as type, location, area, and so forth. Gilroy and McCuen [14] simulated the spatial and quantitative effects of cisterns and bioretention areas using a developed spatio-temporal model and provided information on the spatial arrangements and volumes needed to achieve effective results in reduction of runoff volumes and peak discharge rates. Endreny and Collins [17] examined groundwater recharge and mounding by adjusting the spatial arrangements of bioretention areas as distributed, clustered, and single units using a MODFLOW model in an urban residential area of New York, USA. They determined that groundwater mounding was highest when bioretention areas were arrayed as single units and lowest when they were fully distributed. Brander et al. [9] identified the impact of the number of infiltration practices by demonstrating that runoff differences among different urban types could be overcome by implementing a number of infiltration practices. Ahiablame et al. [18] also evaluated the effects of LID practices on runoff and pollutant loads according to the percent implementation of rain barrel/cistern and porous pavement. While the above studies showed that studies addressing proper distribution and placement of LID practices are needed, none provided an approach that would optimize the area of LID needed, as a function of location and type, to meet a target runoff and pollutant reduction rate.

The establishment of proper watershed-scale strategies for LID conditions is required to obtain optimal results for reductions of runoff volume and nutrient loadings. Cost is an essential factor that must be considered along with the strategies because a restricted budget is usually given for performing the strategies [19]. Gilroy and McCuen [14], in their study, simply determined several scenarios for placing cisterns and bioretention areas according to the places where water was intercepted, and Chaubey et al. [20] stated that random placement was normally used. However, such methods can make a cost-effective scenario for LID conditions (which may result in better outcomes in reduction with minimal cost) be missed as it is among unconsidered scenarios. Liu et al. [21] indicated that they found the best effective scenario of LID and best management practices (BMP) conditions showing the greatest reduction in runoff and pollutant loadings among 16 scenarios, but it was not a cost-effective scenario. Therefore, optimization would be necessary. Many researchers have performed optimization to accomplish the best effect close to a required target reduction goal at minimum cost [19,22-26]. However, most studies have been for optimization of agricultural best management practices (conventional stormwater treatment systems akin to LID practices) and have drawn the optimal scenario (or the best solution) by utilizing various optimization tools, such as the genetic algorithm (GA), through model development. While the use of tools enables evaluation of a myriad of probable options for various LID conditions, it makes the process complex and increases the simulation time [24]. In particular, it becomes an inefficient method when considering just a few conditions or small watersheds. In this regard, a manual technique for optimization is required, which can simplify the complexity and easily provide information on cost-effective LID conditions at any watershed.

The purpose of this study was to present the optimal LID conditions that can attain targeted reduction goals with minimal cost and to evaluate the effectiveness of LID practices under the optimal conditions and the consequential cost on a watershed scale. A manual optimization was conducted for identifying the optimal conditions of LID practices, using a Microsoft Excel spreadsheet. Five targeted reduction goals were determined by using the results of reduction amounts by LID practices from the Soil and Water Assessment Tool (SWAT). Three LID conditions were taken into account in the manual optimization process: types of LID practices (rain gardens, rainwater harvesting tanks, and permeable pavements), locations (residential and commercial areas), and percent allocation of LID practices at each location. The study was processed for surface runoff (SURQ), nitrate $\left(\mathrm{NO}_{3}\right)$, and total phosphorus (TP). 


\section{Materials and Methodology}

\subsection{Case Study Area}

The study was carried out in a small-scale area of approximately 350 ha $\left(3.5 \mathrm{~km}^{2}\right)$, comprised of some portions of League City, Webster, and Friendswood in Harris County, Texas, as a case study. The area is nested within the Clear Creek watershed and is situated at the downstream end of Clear Creek (close to the outlet), which is in an area under the influence of tidal currents (Figure 1). Estuarine areas have generally had more water problems (such as flooding and accumulation of untreated pollutants) than other regions because of their geographical characteristics such as flat topography with low elevations and a tidal-affected location. The area has elevations of 6-8 $\mathrm{m}$ Above Mean Sea Level (AMSL). While current land use is in a pre-development state consisting of hay $(28.23 \%)$, rangeland $(15.35 \%)$, wetland $(30.71 \%)$, and forest $(25.71 \%)$, a new urban area will be developed in this area.

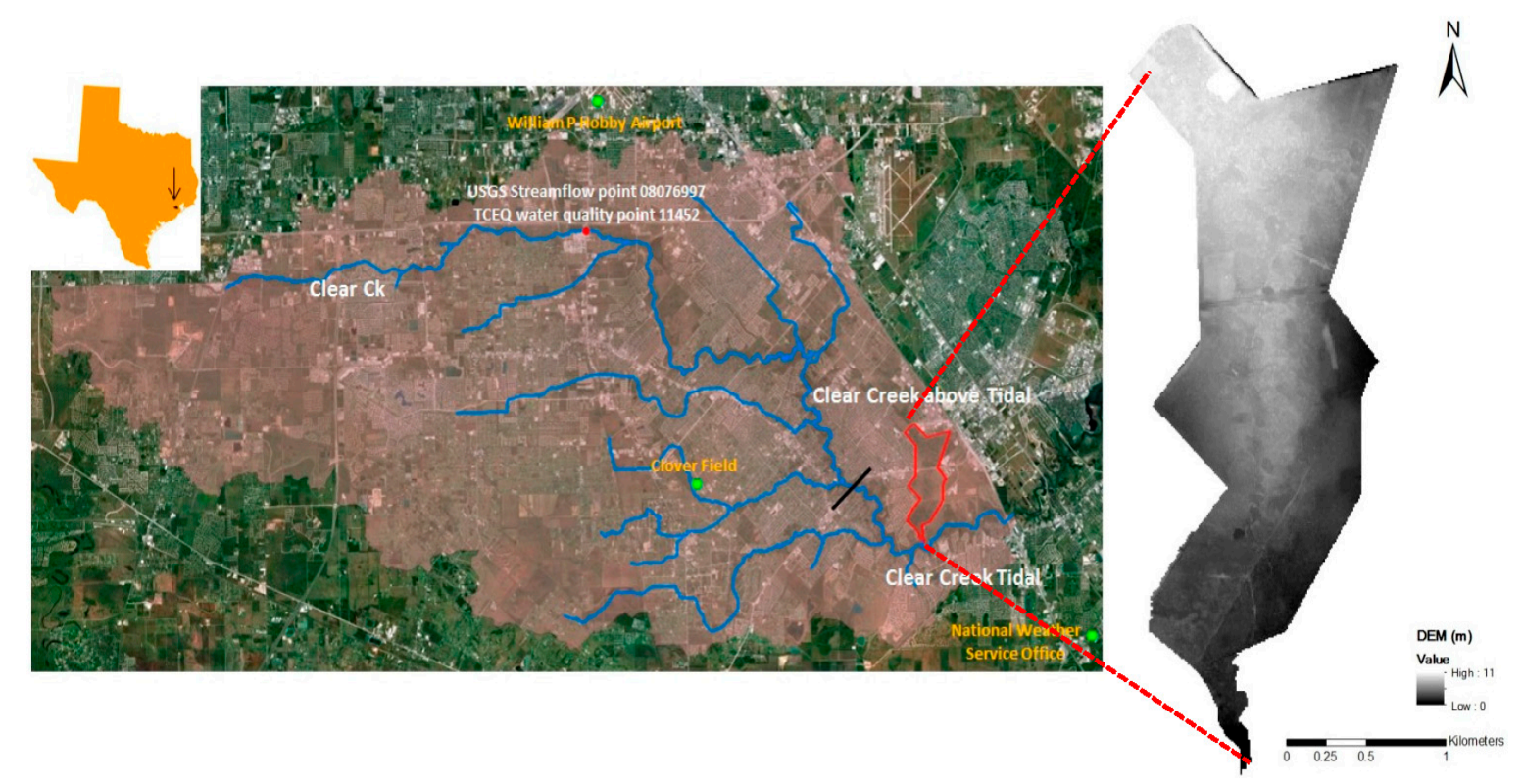

Figure 1. Study area location in the Clear Creek watershed boundary (Three round marks (green) on the map are weather stations, and a short bar (black) is a boundary line for a tidal-affected and non-tidal stream).

The new urban area is a conventional urban form of medium density (Figure 2). It will be constructed with single family neighborhoods and a commercial district. It is one of the urban strategies of League City [27]. Besides the urban areas, the remaining land use is the same as the pre-development state. The soil of the study area is classified into four types: Addicks $(61.4 \%)$, Bernard (27.3\%), Lake Charles (3.2\%), and Aris (8.1\%). The textures of the soils are mainly clay and clay loam, and they all belong to hydrologic soil group (HSG) D, which has very low permeability. Mild winters and hot summers are typical weather patterns for this region. The temperature averages about $12{ }^{\circ} \mathrm{C}\left(53^{\circ} \mathrm{F}\right)$ in January and about $29^{\circ} \mathrm{C}\left(84^{\circ} \mathrm{F}\right)$ in August. The average annual rainfall is approximately $1270 \mathrm{~mm}$, with an average monthly range of about $50-165 \mathrm{~mm}$. Intense rainfall is typical of this region because of its oceanic climate. 


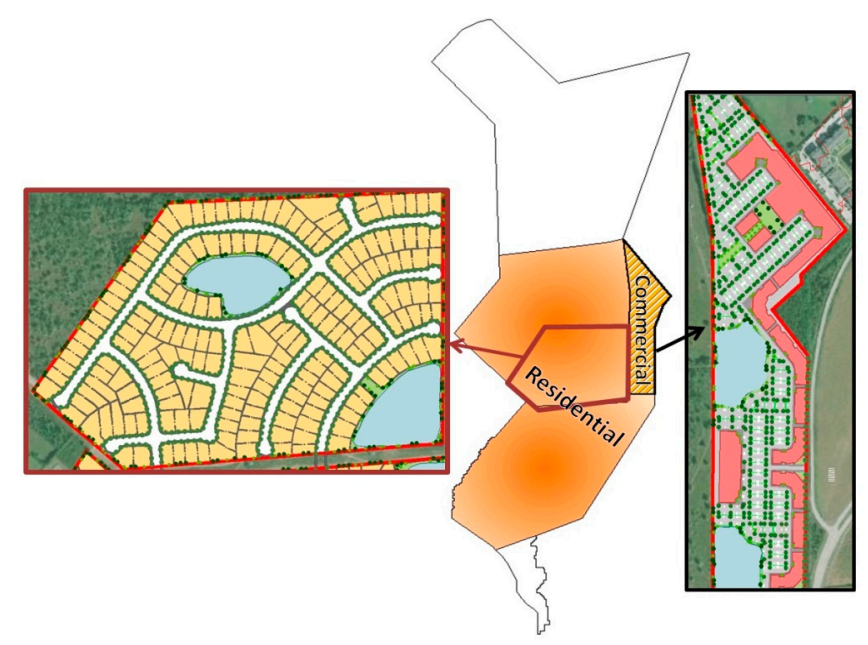

Figure 2. New land use with the conventional urban form of medium density (blowups show residential and commercial patterns, and the empty space is an unchanged natural state).

\subsection{SWAT Model Description and Development}

\subsubsection{Model Description}

The Soil and Water Assessment Tool (SWAT) is a model developed by the United States Department of Agriculture-Agricultural Research Service (USDA-ARS). It has been extensively used to deal with various water quantity and quality problems from many watersheds, and its capability has been verified through results [28-33]. It is applicable to simulations of various sizes of watersheds from small and medium watersheds to large watersheds [28-30]. It can also simulate long and short terms and even sub-daily and sub-hourly time steps [31-33]. As SWAT is a distributed model, it can discretize a watershed as subbasins and smaller hydrologic response units (HRUs), which are the minimum-sized response units. It has essential model components such as surface runoff, infiltration, groundwater, evapotranspiration, nutrient cycling, etc. All components are operated at an HRU level.

Surface runoff can be calculated based on a modified Natural Resources Conservation Service (NRCS) curve number method [34] on a daily basis. Urban surface runoff is estimated respectively for the disconnected impervious/pervious area and for the connected impervious area [35]. The amount of infiltration depends on the amounts of precipitation and surface runoff. That is, it is estimated by excluding surface runoff from rainfall. The infiltrated water is uniformly distributed in a soil layer through a redistribution process. The soil water is percolated at water content above field capacity in the soil layer, and groundwater is recharged by percolation. The amount of actual evaporation from soil is affected by the water content of a soil layer. Sediment and nutrient processes interrelate with the water process. A Modified Universal Soil Loss Equation (MUSLE) [36] predicts sediment yield, and it is a function based on a runoff factor. The transportation of nitrate is influenced by surface runoff, lateral subsurface flow, or percolation. Soil-attached nutrients such as organic and mineral phosphorus and organic nitrogen are governed by sediment yield transported by surface runoff under a loading function $[37,38]$.

\subsubsection{Model Development}

SWAT processes can sufficiently explain hydrologic behavior of LID practices on a watershed scale. In this study, three LID practices including permeable pavements (PPs), rain gardens (RGs), and rainwater harvesting tanks (RWHs) were factored into an urban area. They partially store surface runoff generated from an urban area up to their capacities and discharge water exceeding their capacities as surface runoff. To reflect the hydrologic behavior of the LID practices, surface runoff processes in SWAT were modified based on McCuen's method [39]. In his method, runoff depth stored 
by infiltration practices is excluded from the runoff depth of post-development in order to calculate the modified curve number that reflects the infiltration practices. The idea of the method was incorporated into the surface runoff process as Equation (1):

$$
\mathrm{Q}_{\mathrm{LIDs}}=\mathrm{Q}_{\mathrm{tot}}-\mathrm{LIDval}
$$

where $Q_{\text {tot }}$ is the surface runoff depth $(\mathrm{mm})$ before the application of LID practices, $Q_{\text {LIDs }}$ is the surface runoff depth $(\mathrm{mm})$ after LID practices are reflected, and LIDval is the storage depth $(\mathrm{mm})$ of each type of LID practice.

SWAT effectively represents hydrologic behavior by PPs and RGs under the developed equation. As can be seen in the equation, surface runoff, excluding water stored by PPs and RGs, is computed, and the water stored by PPs and RGs is added to the amount of infiltration. On the other hand, RWHs are simply storage facilities that cannot directly infiltrate the stored water into soil layers, unlike RGs and PPs. Thus, codes were additionally included so that water accrued in the rain barrels and the accumulated water was deliberately drained to reuse them. The rain barrels were defined to be empty after at least 7 consecutive dry days after a rainfall event. A text file that allows for entrance of the storage depths for LID practices was included in a SWAT folder, and an algorithm that could read the text file was coded. Nitrate and total phosphorus were runoff-borne pollutants and were treated along with surface runoff. A detailed description of the representation of LID practices in SWAT can be found in Seo et al. [16].

\subsection{LID Conditions for Optimization}

The three LID practices (PPs, RGs, and RWHs) are building-scale facilities frequently practiced in urbanized areas which have very little space for installation. Each LID practice is site-specific. In this study, they were assumed to address stormwater and the consequential pollutant loadings only from each specific site: RWHs were installed below roofs and harvested runoff and pollutants only from rooftops during rainfall, PPs were considered only in the parking lots of a commercial area and collected runoff and pollutants generated only from parking lots, and RGs were integrated in the backyards of each house or street system such as sidewalks at random and captured runoff and pollutants generated from a residential area.

Each LID practice occupied different areas. In the case of RWHs, the roof area represented the area of RWHs because RWHs deal with runoff only from roofs. The design data from League City offered no information for roof area. Therefore, an average roof area was acquired from similar neighborhoods with a conventional medium-density urban design through sampling in Google Earth, and total roof area was determined by multiplying the average roof area by the number of lots presented from the design data. The total area of RGs was estimated by multiplying a catchment area by a size factor based on soil properties and depths of RGs [40]. The catchment area was applied for each residential subbasin area in which the total roof area was excluded. This process was for the purpose of ruling out runoff addressed by RWHs. The size factor 0.1 was used based on data from Bannerman and Considine [41]. The total area of PPs was dependent on the percentage of parking lot area presented in the commercial area of the design data. Consequently, 20\% (36.37 ha) and 8\% (14.55 ha) of the residential area were considered as the areas for RWHs and RGs, respectively, and $47 \%$ ( 8.57 ha) of the commercial area was taken into account as the area for PPs.

Each LID practice was designed to detain different runoff depths. The maximum storage depths of PPs and RGs were limited to a rainfall size. They were calculated using 1.5 inches $(38.1 \mathrm{~mm})$ of precipitation on each site based on the Curve Number $(\mathrm{CN})$ method. An amount of 1.5 inches of rainfall is the 85th percentile 24-h rainfall depth and it is a value referred to as water quality protection by a stormwater management system in the North Central Texas Council of Governments (NCTCOG) region [42] (For RWHs, 1000-gallon rain barrels were assumed to be used to treat runoff and pollutants from roofs [43]. The volume was reversely divided by the average roof area to estimate 
maximum storage depth. As a result, PPs, RGs, and RWHs were sized to capture 32.52-mm, 19.11-mm, and 12.94-mm runoff depths from each area, respectively. The information for the maximum areas and storage depths of LID practices is summarized in Table 1.

Table 1. Specific information for maximum areas and storage depths of low-impact development (LID) practices. RWHs: rainwater harvesting tanks; RGs: rain gardens; PPs: permeable pavements.

\begin{tabular}{ccccc}
\hline \multirow{2}{*}{ Practices } & $\begin{array}{c}\text { Commercial Area } \\
\text { (Subbasin 2) }\end{array}$ & $\begin{array}{c}\text { Residential Area } \\
\text { (Subbasin 3) }\end{array}$ & $\begin{array}{c}\text { Residential Area } \\
\text { (Subbasin 4) }\end{array}$ & $\begin{array}{c}\text { Storage Depth } \\
\text { of LID Practices } \\
\text { (mm) }\end{array}$ \\
\cline { 2 - 4 } Total subbasin & 18.22 & 83.28 & 98.55 & - \\
RGs & - & 6.66 & 7.88 & 19.11 \\
RWHs & - & 16.66 & 19.71 & 12.94 \\
PPs & 8.57 & - & - & 32.52 \\
\hline
\end{tabular}

\subsection{Modeling Setup}

In this study, "LID-absence" and "LID-presence" mean the post-development state without and with LID practices, respectively. Simulations for LID-absence and LID-presence scenarios were performed for the purpose of identifying the maximum LID benefits which would be ultimately used to set targeted reduction goals. The targeted goals are illustrated in the "Manual Optimization" subsection.

The simulation for the LID-absence scenario was first configured by using several input data. It is desirable to use high spatial resolution data for the simulation of a small study area for producing accurate outputs. A ten by ten-meter digital elevation model (DEM) obtained from the USDA NRCS Geospatial Data Gateway was used to describe topography in detail. For soils, the Soil Survey Geographic Database (SSURGO) from the NRCS Soil Data Mart was applied. The daily rainfall and temperature data of two stations, the National Weather Service Office and the Houston Clover Field, were employed; these were acquired from the National Climate Data Center (NCDC). For humidity, wind speed, and solar radiation, the data from a weather generator, which generates climatic data using monthly mean data of many years, were used. The land use with a conventional urban form of medium density was applied to obtain results in the post-development state. The urban area takes up about $56 \%$ of total area and is separated as residential and commercial areas, which have $44 \%$ and $75 \%$ impervious fractions, respectively. The remaining area (44\%) remains unchanged as a pre-developed area. The land use was represented as 5 subbasins, including 2 subbasins for the residential area and 1 subbasin for the commercial area, and 18 HRUs in total. SWAT was tested for surface runoff, nitrate, and total phosphorus from October 2006 to December 2011. The results of the LID-absence scenario indicated $473.32 \mathrm{~mm}$ for surface runoff, $591.87 \mathrm{~kg}$ for nitrate, and $449.55 \mathrm{~kg}$ for total phosphorus on an average annual basis [16].

The simulation for the LID-presence scenario was performed under the same conditions as for the LID-absence scenario, except for LID conditions. In order to test the LID-presence scenario, three LID facilities were applied in SWAT: RWHs and RGs were considered in the residential area and PPs were only considered in the commercial area. The LID practices were assumed to be fully placed and implemented in the LID areas of Table 1, and seasonal impacts of LID practices were not reflected. The application of LID practices was performed at an HRU level. The existing HRUs of the residential and commercial areas were divided into separate HRUs for roofs and parking lots in order to treat RWHs and PPs. The RGs were considered in the rest of the HRUs of the residential area. In order to divide the HRUs, the percentages for the areas of roofs (20\%) and parking lots (47\%) were multiplied by the existing HRUs. The roofs and parking lots were included as new urban types in the existing urban data of SWAT, and each urban type was applied to the individual specific HRUs. The number representing each LID was also applied to all HRUs that have LID practices. The LID-presence scenario was run by using the modified SWAT, and the effects by LID practices were measured for runoff, nitrate, and total phosphorus on a watershed scale. The LID practices mitigated the surface runoff and 
the consequential pollutants well in urban areas by showing decreased values from the LID-absence scenario. The results of the LID-presence scenario represented $337.81 \mathrm{~mm}$ for surface runoff, $405.85 \mathrm{~kg}$ for nitrate, and $338.86 \mathrm{~kg}$ for total phosphorus on an average annual basis. The detailed information for modeling work can be found in Seo et al. [16]. The differences between the LID-absence and LID-presence scenarios were calculated for all variables to set targeted goals [16].

\subsection{Cost Estimation}

Cost is an important measure for optimization. An annual total cost for each LID practice was estimated as the sum of construction and maintenance costs, based on the following equation by Arabi et al. [19] (Equation (2)):

$$
C_{\mathrm{td}}=\left[\mathrm{C}_{0} \cdot(1+\mathrm{s})^{\mathrm{td}}+\mathrm{C}_{0} \cdot \mathrm{rm} \cdot\left(\frac{(1+\mathrm{s})^{\mathrm{td}}-1}{\mathrm{~s}}\right)\right] / \mathrm{td}
$$

where $C_{t d}$ is the annual cost per unit area during a design life $\left(\$ / \mathrm{ft}^{2} /\right.$ year $), C_{0}$ is the construction cost per unit area $\left(\$ / \mathrm{ft}^{2}\right)$, rm is the proportion of maintenance to construction cost, $\mathrm{s}$ is the interest rate, and $t d$ is the intended life of LID practices based on routine maintenance.

Data for the construction cost per unit area $\left(\$ / \mathrm{ft}^{2}\right)$ were acquired through experiments at the Texas A\&M AgriLife Research and Extension Center in Dallas [44]. The cost of $\$ 6$ per square feet was used for RGs, $\$ 14$ per square feet for PPs, and $\$ 1$ per gallon for RWHs. In the case of RWHs, the cost per gallon was converted to cost per unit area by replacing 1000-gallon rain barrel with the average roof area. The function of LID practices decreases as time passes. Maintenance is thus continuously required to keep the same effectiveness during the life-time of LID practices. For the computation of maintenance costs, annually $5 \%$ was used as the proportion of maintenance of RGs to construction cost. This value was referenced by the US Environmental Protection Agency [45]. In the case of PPs and RWHs that have no reference data, 5\%, the same as for RGs, was used for PPs because a similar maintenance cost was incurred to maintain PPs in the experimental field of the AgriLife center [44], and a 1\% ratio was determined for RWHs due to the low maintenance requirements (cost determined based on several systems constructed and built by Texas A\&M AgriLife Extension). For all LID practices considered, the same interest rate of $4.5 \%$ was considered and the same lifespan of 20 years was applied to the cost calculation. As a result, the annual costs per unit area were estimated as $1.19\left(\$ / \mathrm{ft}^{2} /\right.$ year $)$ for RGs, $2.79\left(\$ / \mathrm{ft}^{2} /\right.$ year $)$ for PPs, and $0.04\left(\$ / \mathrm{ft}^{2} /\right.$ year $)$ for RWHs.

\subsection{Manual Optimization}

\subsubsection{Setting Targeted Goals}

The United States Environmental Protection Agency (USEPA) has conducted a water quality standards program which presents a threshold level to protect water bodies [46]. Under the policy, states and local authorities develop region-specific criteria. However, no recommended criteria exist for runoff or pollutant reductions in the study area and accordingly there is no given budget limitation. Therefore, it was determined that five cases would be used as targeted goals to be controlled for each variable. The targeted goals for each case included the following values: $25 \%, 35 \%, 45 \%, 55 \%$ and $65 \%$ of the maximum reduction amounts for all variables. In the modeling work, the maximum reduction amounts by LID practices were obtained from the difference between the LID-absence and LID-presence scenarios and were $135.51 \mathrm{~mm}$ for surface runoff, $186.03 \mathrm{~kg}$ for nitrate, and $110.69 \mathrm{~kg}$ for total phosphorus as average annual values in the watershed. For Case 1, 25\% of the maximum reduction amounts were targeted as reduction amounts to be managed: $33.88 \mathrm{~mm}$ for surface runoff, $46.51 \mathrm{~kg}$ for nitrate, and $27.67 \mathrm{~kg}$ for total phosphorus. Likewise, Cases 2, 3, 4 and 5 targeted $35 \%, 45 \%$, $55 \%$ and $65 \%$, respectively, of the maximum reduction amounts. The constant difference among cases 
was for facilitating evaluation of the effectiveness of LID practices from the considered LID conditions. The targeted goals for each case are summarized in Table 2.

Table 2. Hypothetical cases for targeted goals.

\begin{tabular}{cccccc}
\hline \multirow{2}{*}{ Variable } & \multicolumn{5}{c}{ Targeted Goal 1 } \\
\cline { 2 - 6 } & Case 1 & Case 2 & Case 3 & Case 4 & Case 5 \\
\hline Surface runoff $(\mathrm{mm})$ & 33.88 & 47.43 & 60.98 & 74.53 & 88.08 \\
Nitrate $(\mathrm{kg})$ & 46.51 & 65.11 & 83.71 & 102.32 & 120.92 \\
Total phosphorus $(\mathrm{kg})$ & 27.67 & 38.74 & 49.81 & 60.88 & 71.95 \\
\hline
\end{tabular}

Note: ${ }^{1}$ Targeted goals for each case were $25 \%, 35 \%, 45 \%, 55 \%$ and $65 \%$ of the maximum reduction amounts by LID practices.

\subsubsection{Optimization Procedure}

For the purpose of identifying the conditions of LID practices that achieve both a targeted goal and minimal cost, a stepwise manual operation for optimization was attempted for all variables. The LID conditions considered were type, location (subbasin), and percent allocation of LID area. Each type and location of LID practices under $100 \%$ allocation were first taken into account to determine a ranking for cost in handling unit reduction in order to ultimately minimize total cost for treating a targeted goal. Step 1: In this study, RGs and RWHs were distributed only in the residential area, which was composed of two subbasins (Subbasin 3 and Subbasin 4), and PPs were placed only in the commercial area, which made up one subbasin (Subbasin 2). Each LID practice was considered in designated subbasins, and thus five cases for the conditions were generated: RGs in Subbasin 3, RGs in Subbasin 4, RWHs in Subbasin 3, RWHs in Subbasin 4, and PPs in Subbasin 2. The SWAT model was run for each case. Step 2: The annual reduction amount by $100 \%$ allocation of LID practices in each case was then investigated through the difference from the LID-absence scenario. Step 3: The annual cost for the implementation of LID practices was estimated for every case by multiplying the annual cost per unit area calculated under the cost equation (Equation (2)) by total LID area of each case (given in Table 1). Step 4: The cost per unit reduction was calculated by dividing the annual cost into the annual reduction amount for every case. Different values were obtained for every case, and they were ranked in the order of least costly to most costly. Step 5: Optimization is then carried out based on the type and location for the ranking of the cost per unit reduction. This was achieved as reduction amounts, according to the percent allocation of LID practices, were accumulated up to the point that a targeted goal was met. Step 6: The cost of each case was then estimated through the product of the reduction amount according to the percent allocation of LID practices and the cost per unit reduction of Step 4. The final total cost (TC) and the final cost per unit reduction (CPR) were obtained respectively by the sum of the costs for each case and by dividing the final total cost into the targeted goal.

With regard to optimization of percent allocation, three constraint conditions were applied to explore the behavior of the effectiveness of LID practices: (1) maximum adoption; (2) medium adoption; and (3) minimum adoption. Maximum adoption means to allow full occupation in given LID areas even if it is not feasible in reality. Medium adoption means to restrict the potential occupation of LID practices to a maximum of 75\% for RGs and RWHs and 50\% for PPs. Thus, reduction amounts which are not addressed by the difference in percent allocation from maximum adoption are passed on to the next rankings. Minimum adoption is to require at least 20\% occupation of LID practices but not to exceed $75 \%$ for RGs and RWHs and $50 \%$ for PPs. In this case, after the $20 \%$ allocation is applied to all rankings, the same process with medium adoption is conducted to address the remaining reduction amount for meeting a targeted goal. The optimization was performed in the same way for targeted goals of all variables under three constraint conditions. Figure 3 and Appendix A provide a stepwise procedure and an example for surface runoff Case 5 under maximum adoption, respectively. 


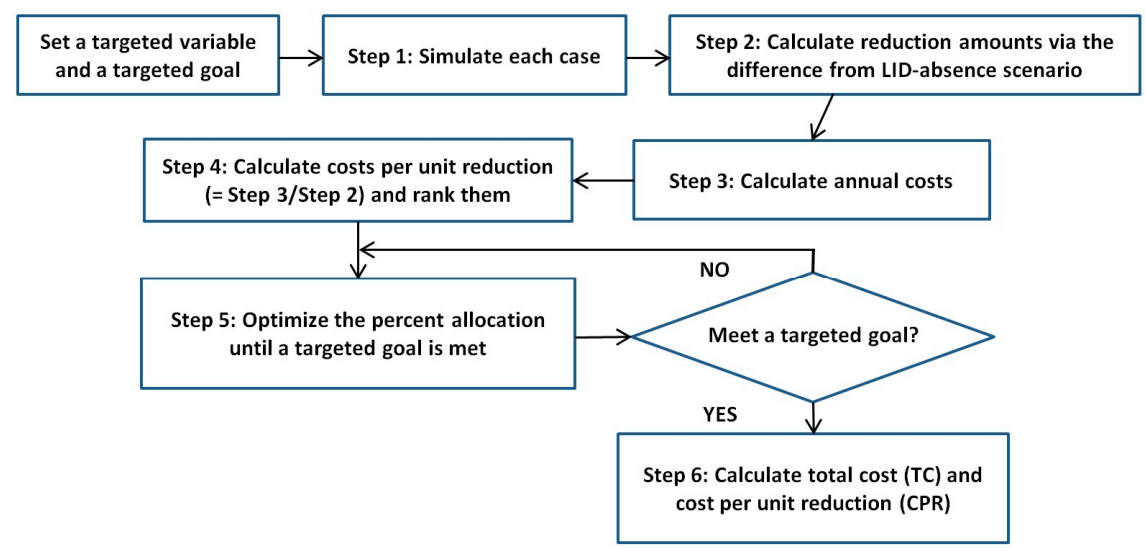

Figure 3. Flow chart for a manual optimization procedure.

\section{Results}

\subsection{Optimized Conditions}

The cost-effective conditions for controlling each targeted goal were determined through the optimization process for all variables (Tables 3-5). A variety of configurations were drawn for each variable. For surface runoff, the optimized conditions were ranked in the order of RWHs (4), RWHs (3), RGs (4), RGs (3), and then PPs (2) (numbers in parentheses mean a location (subbasin) of LID practices, and thus RWHs (4) means RWHs located at Subbasin 4). For nitrate, they were arranged in the order of RWHs (3), RWHs (4), RGs (4), RGs (3), and then PPs (2). In the case of total phosphorus, since the amount reduced by RWHs was tiny compared to the cost for implementation of RWHs, the type of RGs was prioritized to the cost-effective conditions, unlike surface runoff and nitrate: RGs (3), RGs (4), RWHs (4), RWHs (3), and then PPs (2). The type of PPs was ranked last on all occasions because of their high cost. Under these rankings, different percentages of allocation were assigned as seen in Tables 3-5, which met the given targeted goals under three constraint conditions. In surface runoff and nitrate, not only $100 \%$ allocation of RWHs but also the application of RGs was required even to address the smallest targeted goal of Case 1 under the maximum adoption. This was because the RWHs were the most cost-effective but the amount reduced by RWHs was small as described above despite the $100 \%$ allocation at all locations. In total phosphorus, the RGs determined as the most cost-effective condition were only considered in dealing with the targeted goals up to Case 5 under the maximum adoption. Less cost-effective conditions were more considered in the medium and minimum conditions than in the maximum condition for all variables.

\subsection{Analysis of LID Effects}

As can be seen through the optimization results, various combinations of conditions could affect the effectiveness of LID practices. The impact of the optimized LID conditions on the effectiveness of LID practices was observed through the comparison among cases of targeted goals. For example, with regard to the result of maximum adoption for surface runoff (Table 3A), the effectiveness of LID practices in the watershed increased as much as $13.55 \mathrm{~mm}$ in Case 2 by considering 22.62\% more RGs (4) than in Case 1. The effect increased 100\% in Case 3 by extending RG occupation by as much as $45.24 \%$, and increased 200\% in Case 4 as 59.86\% more RGs (4) and 9.99\% more RGs (3) were added compared to Case 1 . An increase of $300 \%$ was also shown in Case 5 as $59.86 \%$ more RGs (4) and 38.28\% more RGs (3) were considered compared to Case 1 . When nitrate was a focused variable (Table $4 \mathrm{~A}$ ), $29.17 \%$ more adoption of RGs (4) than in Case 1 improved the effectiveness of LID practices by $18.6 \mathrm{~kg}$ in Case 2. The effect rose $100 \%$ in Case 3 as $58.34 \%$ more RGs (4) were added than in Case 1 . Also, increases of $200 \%$ and $300 \%$ appeared in Cases 4 and 5, respectively, by further considering 70.13\% more RGs (4) and $21.41 \%$ more RGs (3) and by expanding to $70.13 \%$ more RGs (4) and $57.30 \%$ more RGs (3) than in 
Case 1. In the case of total phosphorus, as seen in Table 5A, the effectiveness of LID practices grew by $11.07 \mathrm{~kg}$ in Case 2 as $27.61 \%$ more RGs (3) were factored than in Case 1, and the effect increased $100 \%$ in Case 3 as 31.04\% more RGs (3) and 20.76\% more RGs (4) were adopted than in Case 1 . In addition, improvements of $200 \%$ and $300 \%$ occurred in Cases 4 and 5 by adoption of $31.04 \%$ more RGs (3) and $44.47 \%$ more RGs (4) and of $31.04 \%$ more RGs (3) and $68.18 \%$ more RGs (4) than in Case 1, respectively.

The impact of the optimized LID conditions on the effectiveness of LID practices was also observed through the comparison among constraint conditions. The result in Case 3 for surface runoff, for example, showed fully occupied LID practices up to Ranking 3 and $18.1 \%$ RGs (3) under the condition of medium adoption in order to meet the same targeted goal as maximum adoption (Table 3B). Under the condition of minimum adoption, $67.52 \%$ RGs (4) were applied to Ranking 3 and the highest and lowest constraint values were applied to the rest of the rankings (Table 3C). The different conditions of LID practices were applied to the medium and minimum conditions, but the result represented that the same effect of LID practices as for the maximum adoption was achieved.

Table 3. Results of optimization for surface runoff (LID type, location, and percent allocation were optimized under the maximum, medium, and minimum constraint conditions, respectively). Sub stands for Subbasin.

\begin{tabular}{cccccccc}
\hline \multicolumn{2}{l}{ (A) Maximum Adoption } & \multicolumn{7}{c}{ \% Allocation } \\
\hline \multirow{2}{*}{ Ranking ${ }^{\mathbf{1}}$} & \multirow{2}{*}{ Type } & \multirow{2}{*}{ Location } & \multicolumn{7}{c}{} \\
\cline { 4 - 8 } & & & Case 1 & Case 2 & Case 3 & Case 4 & Case 5 \\
\hline 1 & RWHs & Sub 4 & 100 & 100 & 100 & 100 & 100 \\
2 & RWHs & Sub 3 & 100 & 100 & 100 & 100 & 100 \\
3 & RGs & Sub 4 & 40.14 & 62.76 & 85.38 & 100 & 100 \\
4 & RGs & Sub 3 & 0 & 0 & 0 & 9.99 & 38.28 \\
5 & PPs & Sub 2 & 0 & 0 & 0 & 0 & 0 \\
\hline
\end{tabular}

\begin{tabular}{cccccccc}
\hline \multicolumn{2}{l}{ (B) Medium Adoption } & \multicolumn{7}{c}{ \% Allocation } \\
\hline \multirow{2}{*}{ Ranking } & \multirow{2}{*}{ Type } & \multirow{2}{*}{ Location } & \multicolumn{7}{c}{} \\
\cline { 3 - 8 } & & & Case 1 & Case 2 & Case 3 & Case 4 & Case 5 \\
\hline 1 & RWHs & Sub 4 & 75 & 75 & 75 & 75 & 75 \\
2 & RWHs & Sub 3 & 75 & 75 & 75 & 75 & 75 \\
3 & RGs & Sub 4 & 44.24 & 66.86 & 75 & 75 & 75 \\
4 & RGs & Sub 3 & 0 & 0 & 18.1 & 46.39 & 74.68 \\
5 & PPs & Sub 2 & 0 & 0 & 0 & 0 & 0 \\
\hline
\end{tabular}

\begin{tabular}{|c|c|c|c|c|c|c|c|}
\hline \multicolumn{8}{|c|}{ (C) Minimum Adoption } \\
\hline \multirow{2}{*}{ Ranking } & \multirow{2}{*}{ Type } & \multirow{2}{*}{ Location } & \multicolumn{5}{|c|}{$\%$ Allocation } \\
\hline & & & Case 1 & Case 2 & Case 3 & Case 4 & Case 5 \\
\hline 1 & RWHs & Sub 4 & 75 & 75 & 75 & 75 & 75 \\
\hline 2 & RWHs & Sub 3 & 75 & 75 & 75 & 75 & 75 \\
\hline 3 & RGs & Sub 4 & 22.28 & 44.9 & 67.52 & 75 & 75 \\
\hline 4 & RGs & Sub 3 & 20 & 20 & 20 & 38.93 & 67.21 \\
\hline 5 & PPs & Sub 2 & 20 & 20 & 20 & 20 & 20 \\
\hline
\end{tabular}

Note: ${ }^{1}$ Ranking is the order of least costly to most costly in handling unit reduction, and optimization was conducted in the order of the rankings up to the point that targeted goals were met.

Table 4. Results of optimization for nitrate (LID type, location, and percent allocation were optimized under the maximum, medium, and minimum constraint conditions, respectively).

\begin{tabular}{cccccccc}
\hline \multicolumn{2}{l}{ (A) Maximum Adoption } & \multicolumn{7}{c}{ \% Allocation } \\
\hline \multirow{2}{*}{ Ranking $^{1}$} & \multirow{2}{*}{ Type } & \multirow{2}{*}{ Location } & \multicolumn{7}{c}{} \\
\cline { 4 - 8 } & & & Case 1 & Case 2 & Case 3 & Case 4 & Case 5 \\
\hline 1 & RWHs & Sub 3 & 100 & 100 & 100 & 100 & 100 \\
2 & RWHs & Sub 4 & 100 & 100 & 100 & 100 & 100 \\
3 & RGs & Sub 4 & 29.87 & 59.04 & 88.21 & 100 & 100 \\
4 & RGs & Sub 3 & 0 & 0 & 0 & 21.41 & 57.3 \\
5 & PPs & Sub 2 & 0 & 0 & 0 & 0 & 0 \\
\hline
\end{tabular}


Table 4. Cont

\begin{tabular}{|c|c|c|c|c|c|c|c|}
\hline \multicolumn{8}{|c|}{ (B) Medium Adoption } \\
\hline \multirow{2}{*}{ Ranking } & \multirow{2}{*}{ Type } & \multirow{2}{*}{ Location } & \multicolumn{5}{|c|}{$\%$ Allocation } \\
\hline & & & Case 1 & Case 2 & Case 3 & Case 4 & Case 5 \\
\hline 1 & RWHs & Sub 3 & 75 & 75 & 75 & 75 & 75 \\
\hline 2 & RWHs & Sub 4 & 75 & 75 & 75 & 75 & 75 \\
\hline 3 & RGs & Sub 4 & 40.64 & 69.81 & 75 & 75 & 75 \\
\hline 4 & RGs & Sub 3 & 0 & 0 & 29.51 & 65.42 & 75 \\
\hline 5 & PPs & Sub 2 & 0 & 0 & 0 & 0 & 29.06 \\
\hline \multicolumn{8}{|c|}{ (C) Minimum Adoption } \\
\hline \multirow{2}{*}{ Ranking } & \multirow{2}{*}{ Type } & \multirow{2}{*}{ Location } & \multicolumn{5}{|c|}{$\%$ Allocation } \\
\hline & & & Case 1 & Case 2 & Case 3 & Case 4 & Case 5 \\
\hline 1 & RWHs & Sub 3 & 75 & 75 & 75 & 75 & 75 \\
\hline 2 & RWHs & Sub 4 & 28.21 & 75 & 75 & 75 & 75 \\
\hline 3 & RGs & Sub 4 & 20 & 38.84 & 68.01 & 75 & 75 \\
\hline 4 & RGs & Sub 3 & 20 & 20 & 20 & 47.31 & 75 \\
\hline 5 & PPs & Sub 2 & 20 & 20 & 20 & 20 & 29.06 \\
\hline
\end{tabular}

Note: ${ }^{1}$ Refer to the annotation in Table 3.

Table 5. Results of optimization for total phosphorus (LID type, location, and percent allocation were optimized under the maximum, medium, and minimum constraint conditions, respectively).

\begin{tabular}{|c|c|c|c|c|c|c|c|}
\hline \multicolumn{8}{|c|}{ (A) Maximum Adoption } \\
\hline \multirow{2}{*}{ Ranking ${ }^{1}$} & \multirow{2}{*}{ Type } & \multirow{2}{*}{ Location } & \multicolumn{5}{|c|}{$\%$ Allocation } \\
\hline & & & Case 1 & Case 2 & Case 3 & Case 4 & Case 5 \\
\hline 1 & RGs & Sub 3 & 68.96 & 96.57 & 100 & 100 & 100 \\
\hline 2 & RGs & Sub 4 & 0 & 0 & 20.76 & 44.47 & 68.18 \\
\hline 3 & RWHs & Sub 4 & 0 & 0 & 0 & 0 & 0 \\
\hline 4 & RWHs & Sub 3 & 0 & 0 & 0 & 0 & 0 \\
\hline 5 & PPs & Sub 2 & 0 & 0 & 0 & 0 & 0 \\
\hline \multicolumn{8}{|c|}{ (B) Medium Adoption } \\
\hline \multirow{2}{*}{ Ranking } & \multirow{2}{*}{ Type } & \multirow{2}{*}{ Location } & \multicolumn{5}{|c|}{$\%$ Allocation } \\
\hline & & & Case 1 & Case 2 & Case 3 & Case 4 & Case 5 \\
\hline 1 & RGs & Sub 3 & 68.96 & 75 & 75 & 75 & 75 \\
\hline 2 & RGs & Sub 4 & 0 & 18.53 & 42.24 & 65.95 & 75 \\
\hline 3 & RWHs & Sub 4 & 0 & 0 & 0 & 0 & 75 \\
\hline 4 & RWHs & Sub 3 & 0 & 0 & 0 & 0 & 75 \\
\hline 5 & PPs & Sub 2 & 0 & 0 & 0 & 0 & 36.3 \\
\hline \multicolumn{8}{|c|}{ (C) Minimum Adoption } \\
\hline \multirow{2}{*}{ Ranking } & \multirow{2}{*}{ Type } & \multirow{2}{*}{ Location } & \multicolumn{5}{|c|}{$\%$ Allocation } \\
\hline & & & Case 1 & Case 2 & Case 3 & Case 4 & Case 5 \\
\hline 1 & RGs & Sub 3 & 38.07 & 65.68 & 75 & 75 & 75 \\
\hline 2 & RGs & Sub 4 & 20 & 20 & 35.7 & 59.4 & 75 \\
\hline 3 & RWHs & Sub 4 & 20 & 20 & 20 & 20 & 75 \\
\hline 4 & RWHs & Sub 3 & 20 & 20 & 20 & 20 & 75 \\
\hline 5 & PPs & Sub 2 & 20 & 20 & 20 & 20 & 36.3 \\
\hline
\end{tabular}

Note: ${ }^{1}$ Refer to the annotation in Table 3.

\subsection{Analysis of Costs}

Final total cost (TC) and cost per unit reduction (CPR) generated from the optimized conditions were compared and analyzed. All results displayed were the minimal costs that treated the given targeted goals (Table 6 and Figure 4). In the comparison among three constraint conditions (that is, the conditions that indicated the same effectiveness of LID practices), the maximum condition showed the lowest TC and the lowest CPR for all cases and for all variables. This was a natural result because more adoption of cost-effective LID conditions was possible in controlling the same targeted goal under 
the maximum condition as compared to the medium and minimum conditions. The maximum and medium conditions presented similar TC while the minimum condition indicated a large difference from the maximum and medium conditions (Figure 4). This was because $20 \%$ of the expensive PP was applied under the minimum adoption for all cases. In the medium adoption of nitrate and total phosphorus, abrupt increases in Case 5 could be also explained due to the application of PPs. Meanwhile, in the comparison among the cases of targeted goals (that is, the conditions that indicated the variation of the effectiveness of LID practices), the lowest TC and the lowest CPR resulted in Case 1 for all variables under the maximum and medium conditions. This was due to the fact that the more a targeted reduction amount was increased, the more the total cost and the consequential cost per unit reduction increased. The minimum adoption showed the same trend in TC. However, it presented the lowest CPR in Case 5 for surface runoff and in Case 4 for nitrate and total phosphorus and the highest CPR in Case 1 for all variables (Figure 4). This was seen because unlike the maximum and medium conditions, the cost-effective conditions were ignored in up to $20 \%$ adoption in all cases under the minimum adoption, and relatively expensive PPs compared to the other LID practices were compulsorily considered. With regard to nitrate and total phosphorus, the reason why Case 4 was more cost-effective than Case 5 was also attributable to a higher percent occupation of PPs in Case 5. That is, the increase of the total cost was significant compared to the increase of the targeted reduction amount.

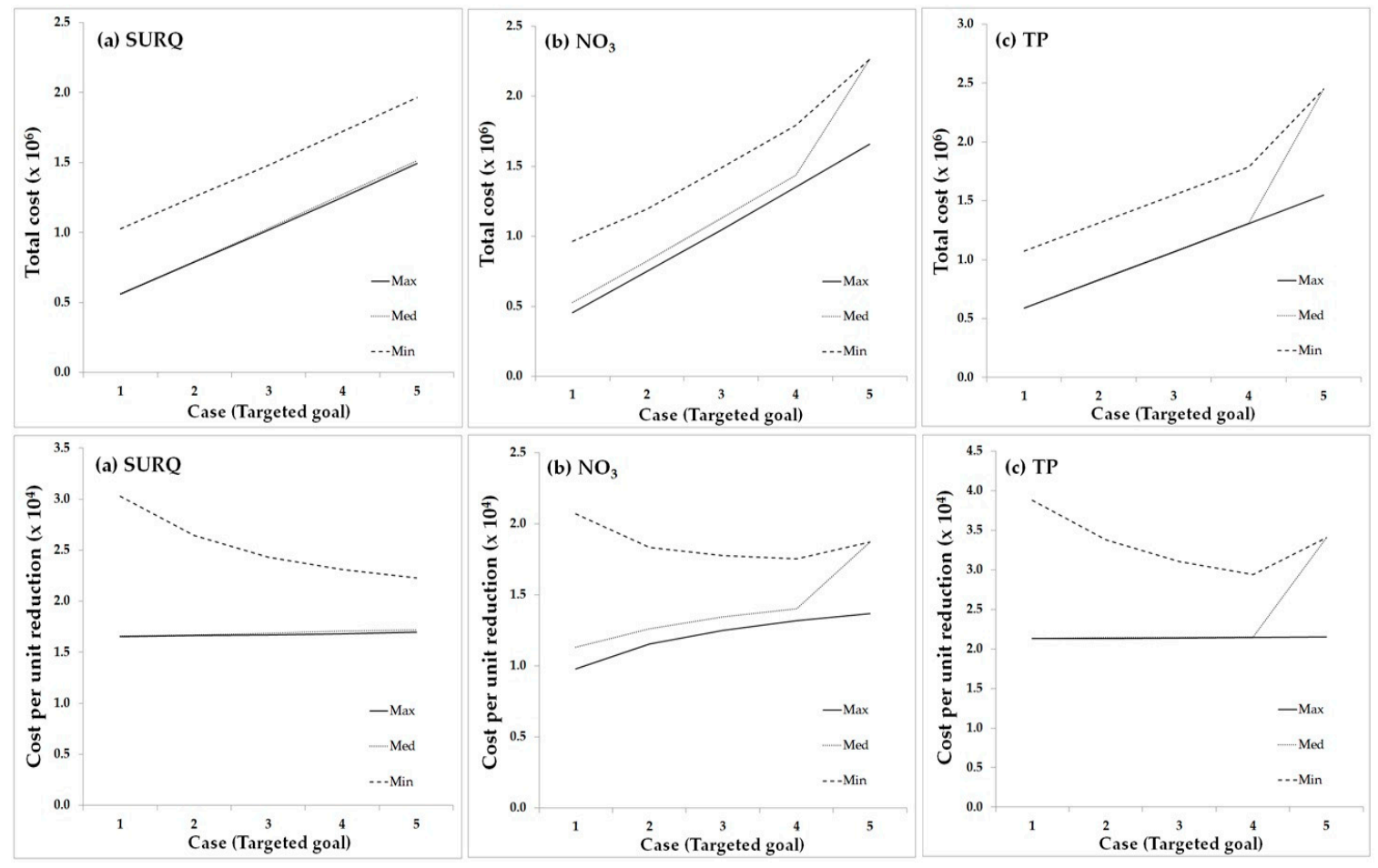

Figure 4. Annual total cost (TC) and cost per unit reduction (CPR) for all targeted goals under three constraint conditions: (a) surface runoff (SURQ); (b) nitrate; and (c) total phosphorus (they are simply schematized in Table 6). 
Table 6. Annual total cost and cost per unit reduction from optimized LID conditions for all targeted goals under three constraint conditions.

\begin{tabular}{|c|c|c|c|c|c|c|c|}
\hline \multirow{2}{*}{ Case } & \multirow{2}{*}{ Variable } & \multicolumn{2}{|c|}{ Maximum Adoption } & \multicolumn{2}{|c|}{ Medium Adoption } & \multicolumn{2}{|c|}{ Minimum Adoption } \\
\hline & & $\mathrm{TC}^{1}$ & $\mathrm{CPR}^{1}$ & TC & CPR & TC & CPR \\
\hline 5 & \multirow{5}{*}{ Surface runoff } & $1,493,527.83$ & $16,956.54$ & $1,513,759.76$ & $17,186.24$ & $1,963,588.64$ & $22,293.30$ \\
\hline 4 & & $1,251,284.14$ & $16,789.22$ & $1,271,516.07$ & $17,060.68$ & $1,721,430.57$ & $23,097.45$ \\
\hline 3 & & $1,017,591.16$ & $16,687.76$ & $1,029,336.60$ & $16,880.38$ & $1,483,537.77$ & $24,328.95$ \\
\hline 2 & & $788,374.34$ & $16,622.70$ & $791,769.48$ & $16,694.29$ & $1,254,320.94$ & $26,447.09$ \\
\hline 1 & & $559,157.51$ & $16,505.60$ & $562,628.65$ & $16,608.06$ & $1,025,104.12$ & $30,259.74$ \\
\hline 5 & \multirow{5}{*}{$\mathrm{NO}_{3}$} & $1,656,393.69$ & $13,698.51$ & $2,263,032.20$ & $18,715.45$ & $2,263,032.20$ & $18,715.45$ \\
\hline 4 & & $1,349,072.15$ & $13,185.47$ & $1,434,446.15$ & $14,019.89$ & $1,793,187.45$ & $17,526.13$ \\
\hline 3 & & $1,046,268.60$ & $12,498.38$ & $1,126,953.36$ & $13,462.21$ & $1,488,503.12$ & $17,781.17$ \\
\hline 2 & & $750,678.20$ & $11,529.45$ & $821,713.58$ & $12,620.47$ & $1,192,912.72$ & $18,321.61$ \\
\hline 1 & & $455,087.80$ & 9785.39 & $526,072.52$ & $11,311.72$ & $963,350.07$ & $20,714.15$ \\
\hline 5 & \multirow{5}{*}{$\mathrm{TP}$} & $1,547,180.52$ & $21,504.95$ & $2,449,017.71$ & $34,039.98$ & $2,449,017.71$ & $34,039.98$ \\
\hline 4 & & $1,306,918.32$ & $21,468.24$ & $1,310,485.93$ & $21,526.85$ & $1,788,390.63$ & $29,377.20$ \\
\hline 3 & & $1,066,656.12$ & $21,415.22$ & $1,070,249.06$ & $21,487.36$ & $1,548,229.76$ & $31,083.77$ \\
\hline 2 & & $826,916.70$ & $21,345.41$ & $829,936.20$ & $21,423.35$ & $1,309,329.87$ & $33,798.06$ \\
\hline 1 & & $590,495.76$ & $21,339.66$ & $590,517.17$ & $21,340.43$ & $1,072,908.94$ & $38,773.37$ \\
\hline
\end{tabular}

Note: ${ }^{1} \mathrm{TC}$ means total cost (\$), and CPR means cost per unit reduction; the unit is $\$ / \mathrm{mm}$ for surface runoff and $\$ / \mathrm{kg}$ for nitrate and total phosphorus (TP).

\section{Impact of LID Use on Detention Requirements and Cost}

Thus far, the effectiveness of LID practices and the consequential costs according to the optimized LID conditions have been analyzed. However, the water volumes detained by LID practices under the optimized conditions are small (Table 7) because the maximum capacities and allowable areas of LID practices are limited. Thus, for heavy rainfall, a considerable amount of water that is not treated by LID practices would be generated as surface runoff, directly entering channels. Such a large amount of water that cannot be detained by LID practices needs to be taken into account by other methods for controlling stormwater in the region. Therefore, detention ponds were incorporated in the study area to reflect the water volume that could not be addressed by LID practices, and 100-year 24-h rainfall (13 inches) was assumed in this region as the standard for heavy rainfall for the purpose of calculating the volume that should be captured by detention ponds. First, the required detention volume by urbanization was estimated by the difference between pre- and post-development states in surface runoff. The volume that should be captured by detention ponds was then calculated by subtracting the volume detained by LID practices from the required detention volume. The total cost of detention ponds for addressing the calculated volume capacity was calculated using the following equation developed by Brown and Schueler [47] (Equation (3)):

$$
\mathrm{C}=24.5 \times \mathrm{V}^{0.705}
$$

where $\mathrm{C}$ is the establishment cost including construction, design, and authorization (\$) and V is the pond volume $\left(\mathrm{ft}^{3}\right)$. For the calculation of annual cost, a $5 \%$ ratio for maintenance $(\mathrm{rm})$ and a design life of 20 years (td), obtained from the USEPA website, were considered and the same interest rate (s) of $4.5 \%$ was applied. Additionally, the cost savings for the amount controlled by LID practices was computed by the difference between the costs for the calculated detention volume and the required detention volume. Total cost of detention ponds was greatest in Case 1 and accordingly cost savings were the smallest in Case 1 (Figure 5). This was because the volume that should be captured by detention ponds was increased by the smallest volume detained by LID practices in Case 1 . The same trend was indicated in all variables and all constraint conditions. Total phosphorus showed the greatest difference in the cost of detention ponds between Case 4 and Case 5 under the medium and minimum conditions. This was seen because the difference in the optimized LID conditions between two cases 
caused the difference in the volume detained by LID practices. The volume detained by LID practices is affected by percent allocation and storage depth of LID practices, and thus it could vary depending on the optimized LID conditions even with the same targeted goal. Why the costs of detention ponds in total phosphorus were higher than those in the other variables could also be explained by the results of the optimized LID conditions.

LID practices installed in urban areas generally are more expensive than detention ponds. This study does not to compare LID practices to detention ponds. City authorities are being forced to deal with stormwater generated from their regions for new urban developments. Thus, this section presented the volumes that should be captured (that is, the volumes that exceed LID capacities) for heavy rainfall and the consequential costs using detention ponds as a secondary stormwater management method.

Table 7. Volume detained by detention ponds and the consequential cost and cost savings in detention ponds for the amount controlled by LID practices for all cases of all variables under each constraint condition. Ac-ft/ac stands for Acre-feet per acre.

\begin{tabular}{|c|c|c|c|c|c|}
\hline Case & Variable & $\begin{array}{c}\text { Volume Detained } \\
\text { by LID Practices } \\
\text { (ac-ft/ac) }\end{array}$ & $\begin{array}{c}\text { Volume Detained } \\
\text { by Detention Ponds } \\
\text { (ac-ft/ac) }\end{array}$ & $\begin{array}{c}\text { Cost } \\
\text { (\$/Year) }\end{array}$ & $\begin{array}{c}\text { Cost Savings } \\
\text { (\$/Year) }\end{array}$ \\
\hline \multicolumn{6}{|c|}{ (A) Maximum Adoption } \\
\hline 5 & \multirow{5}{*}{ Surface runoff } & $0.0110(7 \%)^{1}$ & $0.1429(93 \%)$ & $243,339.92$ & $13,050.24$ \\
\hline 4 & & $0.0104(7 \%)$ & $0.1434(93 \%)$ & $244,048.85$ & $12,341.31$ \\
\hline 3 & & $0.0098(6 \%)$ & $0.1440(94 \%)$ & $244,731.94$ & $11,658.22$ \\
\hline 2 & & $0.0093(6 \%)$ & $0.1446(94 \%)$ & $245,401.17$ & $10,988.99$ \\
\hline 1 & & $0.0087(6 \%)$ & $0.1451(94 \%)$ & $246,069.64$ & $10,320.51$ \\
\hline 5 & \multirow{5}{*}{$\mathrm{NO}_{3}$} & $0.0114(7 \%)$ & $0.1425(93 \%)$ & $242,862.80$ & $13,527.36$ \\
\hline 4 & & $0.0106(7 \%)$ & $0.1432(93 \%)$ & $243,762.77$ & $12,627.39$ \\
\hline 3 & & $0.0099(6 \%)$ & $0.1439(94 \%)$ & $244,648.16$ & $11,742.00$ \\
\hline 2 & & $0.0092(6 \%)$ & $0.1447(94 \%)$ & $245,511.16$ & $10,879.00$ \\
\hline 1 & & $0.0085(6 \%)$ & $0.1454(94 \%)$ & $246,372.89$ & $10,017.26$ \\
\hline 5 & \multirow{5}{*}{$\mathrm{TP}$} & $0.0038(2 \%)$ & $0.1501(98 \%)$ & $251,941.30$ & 4448.86 \\
\hline 4 & & $0.0032(2 \%)$ & $0.1507(98 \%)$ & $252,634.31$ & 3755.85 \\
\hline 3 & & $0.0026(2 \%)$ & $0.1512(98 \%)$ & $253,326.52$ & 3063.63 \\
\hline 2 & & $0.0020(1 \%)$ & $0.1518(99 \%)$ & $254,016.45$ & 2373.71 \\
\hline 1 & & $0.0014(1 \%)$ & $0.1524(99 \%)$ & $254,696.05$ & 1694.11 \\
\hline \multicolumn{6}{|c|}{ (B) Medium Adoption } \\
\hline 5 & \multirow{5}{*}{ Surface runoff } & $0.0092(6 \%)$ & $0.1446(94 \%)$ & $245,482.09$ & $10,908.07$ \\
\hline 4 & & $0.0086(6 \%)$ & $0.1452(94 \%)$ & $246,188.43$ & $10,201.73$ \\
\hline 3 & & $0.0080(5 \%)$ & 0.1458 (95\%) & $246,893.92$ & 9496.23 \\
\hline 2 & & $0.0074(5 \%)$ & $0.1464(95 \%)$ & $247,584.71$ & 8805.45 \\
\hline 1 & & $0.0069(4 \%)$ & $0.1470(96 \%)$ & $248,250.71$ & 8139.45 \\
\hline 5 & \multirow{5}{*}{$\mathrm{NO}_{3}$} & $0.0105(7 \%)$ & $0.1433(93 \%)$ & $243,883.47$ & $12,506.69$ \\
\hline 4 & & $0.0090(6 \%)$ & $0.1448(94 \%)$ & $245,713.38$ & $10,676.77$ \\
\hline 3 & & $0.0083(5 \%)$ & $0.1456(95 \%)$ & $246,609.48$ & 9780.67 \\
\hline 2 & & $0.0075(5 \%)$ & $0.1463(95 \%)$ & $247,497.80$ & 8892.36 \\
\hline 1 & & $0.0068(4 \%)$ & $0.1470(96 \%)$ & $248,356.64$ & 8033.52 \\
\hline 5 & \multirow{5}{*}{ TP } & $0.0109(7 \%)$ & $0.1430(93 \%)$ & $243,486.50$ & $12,903.66$ \\
\hline 4 & & $0.0032(2 \%)$ & $0.1506(98 \%)$ & $252,623.95$ & 3766.21 \\
\hline 3 & & $0.0026(2 \%)$ & $0.1512(98 \%)$ & $253,316.18$ & 3073.98 \\
\hline 2 & & $0.0020(1 \%)$ & $0.1518(99 \%)$ & $254,007.62$ & 2382.54 \\
\hline 1 & & $0.0014(1 \%)$ & $0.1524(99 \%)$ & $254,696.05$ & 1694.11 \\
\hline
\end{tabular}


Table 7. Cont.

\begin{tabular}{|c|c|c|c|c|c|}
\hline Case & Variable & $\begin{array}{l}\text { Volume Detained } \\
\text { by LID Practices } \\
\text { (ac-ft/ac) }\end{array}$ & $\begin{array}{l}\text { Volume Detained } \\
\text { by Detention Ponds } \\
\text { (ac-ft/ac) }\end{array}$ & $\begin{array}{c}\text { Cost } \\
(\$ / Y e a r)\end{array}$ & $\begin{array}{l}\text { Cost Savings } \\
\text { (\$/Year) }\end{array}$ \\
\hline \multicolumn{6}{|c|}{ (C) Minimum Adoption } \\
\hline 5 & \multirow{5}{*}{ Surface runoff } & $0.0100(6 \%)$ & $0.1439(94 \%)$ & $244,574.79$ & $11,815.37$ \\
\hline 4 & & $0.0094(6 \%)$ & $0.1445(94 \%)$ & $245,281.97$ & $11,108.18$ \\
\hline 3 & & $0.0088(6 \%)$ & $0.1451(94 \%)$ & $245,975.87$ & $10,414.29$ \\
\hline 2 & & $0.0082(5 \%)$ & $0.1456(95 \%)$ & $246,643.69$ & 9746.47 \\
\hline 1 & & $0.0077(5 \%)$ & $0.1462(95 \%)$ & $247,310.75$ & 9079.40 \\
\hline 5 & \multirow{5}{*}{$\mathrm{NO}_{3}$} & $0.0105(7 \%)$ & $0.1433(93 \%)$ & $243,883.47$ & $12,506.69$ \\
\hline 4 & & $0.0095(6 \%)$ & $0.1443(94 \%)$ & $245,072.51$ & $11,317.65$ \\
\hline 3 & & $0.0088(6 \%)$ & $0.1450(94 \%)$ & $245,961.40$ & $10,428.76$ \\
\hline 2 & & $0.0081(5 \%)$ & $0.1458(95 \%)$ & $246,822.47$ & 9567.68 \\
\hline 1 & & $0.0057(4 \%)$ & $0.1482(96 \%)$ & $249,707.61$ & 6682.55 \\
\hline 5 & \multirow{5}{*}{$\mathrm{TP}$} & $0.0109(7 \%)$ & $0.1430(93 \%)$ & $243,486.50$ & $12,903.66$ \\
\hline 4 & & $0.0055(4 \%)$ & $0.1483(96 \%)$ & $249,904.20$ & 6485.96 \\
\hline 3 & & $0.0049(3 \%)$ & $0.1489(97 \%)$ & $250,599.27$ & 5790.89 \\
\hline 2 & & $0.0043(3 \%)$ & $0.1495(97 \%)$ & $251,289.89$ & 5100.27 \\
\hline 1 & & $0.0037(2 \%)$ & $0.1501(98 \%)$ & $251,972.56$ & 4417.59 \\
\hline
\end{tabular}

Note: ${ }^{1}$ Parentheses include percentages of the volume detained by LID practices and the volume detained by detention ponds.

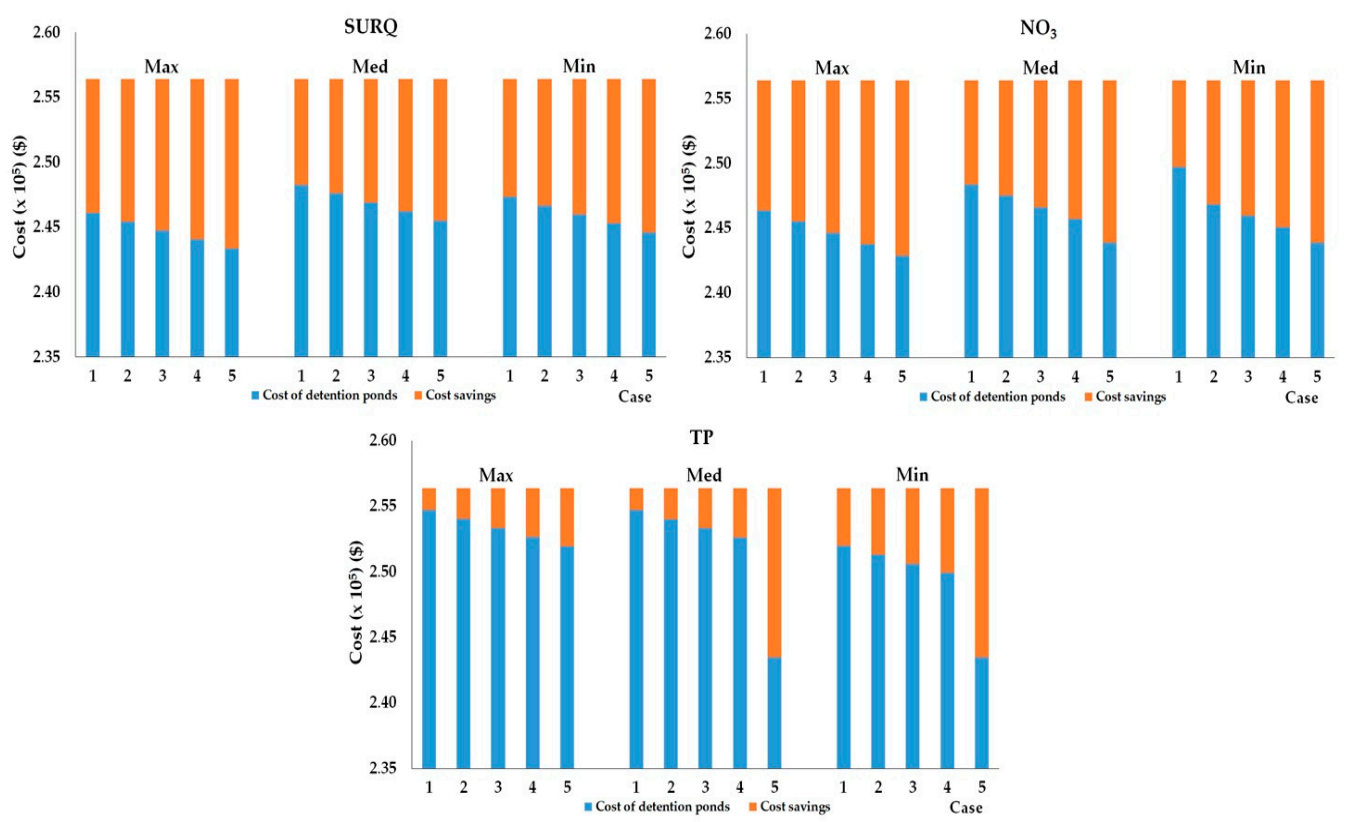

Figure 5. Cost of detention ponds and cost savings for the amount controlled by LID practices for all cases of all variables under each constraint condition (they are simply schematized in Table 7).

\section{Conclusions}

The study has presented the cost-effective LID conditions found through optimization and has analyzed the effectiveness of LID practices on a watershed scale and the consequential costs. To attain the goal, five targeted goals were set and LID conditions for type, location, and percent allocation were optimized. The optimization ultimately came up with the most cost-effective and efficient guidelines for LID planning in the study watershed. For example, if the region is given a budget of $\$ 600,000$ in dealing with surface runoff, it could consider the LID conditions of Case 1 for both maximum and medium conditions. Or, if the region decides to allow maximum adoption to treat the targeted goal, Case 3, for nitrate, it could apply the LID conditions of Case 3 and need at least $\$ 1,047,000$. 
In general, what could be learned through the study was that maximizing the treatment effect of each LID practice should be a priority as cost benefits increase linearly for each unit of surface runoff that is captured. For each LID practice that is implemented, water managers thus need to focus on maximizing the amount of runoff captured for each plot in order to increase cost effectiveness. In addition, the cost-effective results of this study would be generated differently by other conditions such as different types of LID practices besides RGs, PPs and RWHs, different limitations for the allocation of LID practices, different treatment goals, watershed characteristics, and so forth. Therefore, adequate studies for a variety of conditions should be done in advance to achieve cost-effective results within a given budget before the installation of LID practices. Such studies would likely suggest planning and design of LID projects that accomplish a balance between environmental and economic aspects on a development or watershed scale.

As accounted for in the Manual Optimization section, the optimization method employed is very simple and practical in providing cost-effective conditions. It is likely that this method would be applicable in many studies and would easily assist watershed managers in determining the best solution for the establishment of LID practices for their watershed management. In addition, this study has been based on simple calculations using the results of modeling work. If field work had been performed, it would have been possible to validate our results. Such an additional study would be a very meaningful work in that it could lay the groundwork for studies on other watersheds.

Supplementary Materials: The following are available online at www.mdpi.com/2073-4441/9/4/270/s1.

Acknowledgments: The authors would like to thank the Texas Sea Grant college program and TCEQ for their financial support and the Korean National Institute of Agricultural Sciences (PJ010867) for their help.

Author Contributions: Mijin Seo and Fouad Jaber designed the project; Mijin Seo performed the modeling; Mijin Seo, Fouad Jaber and Raghavan Srinivasan analyzed the data and wrote the paper.

Conflicts of Interest: The authors declare no conflict of interest.

\section{Appendix A}

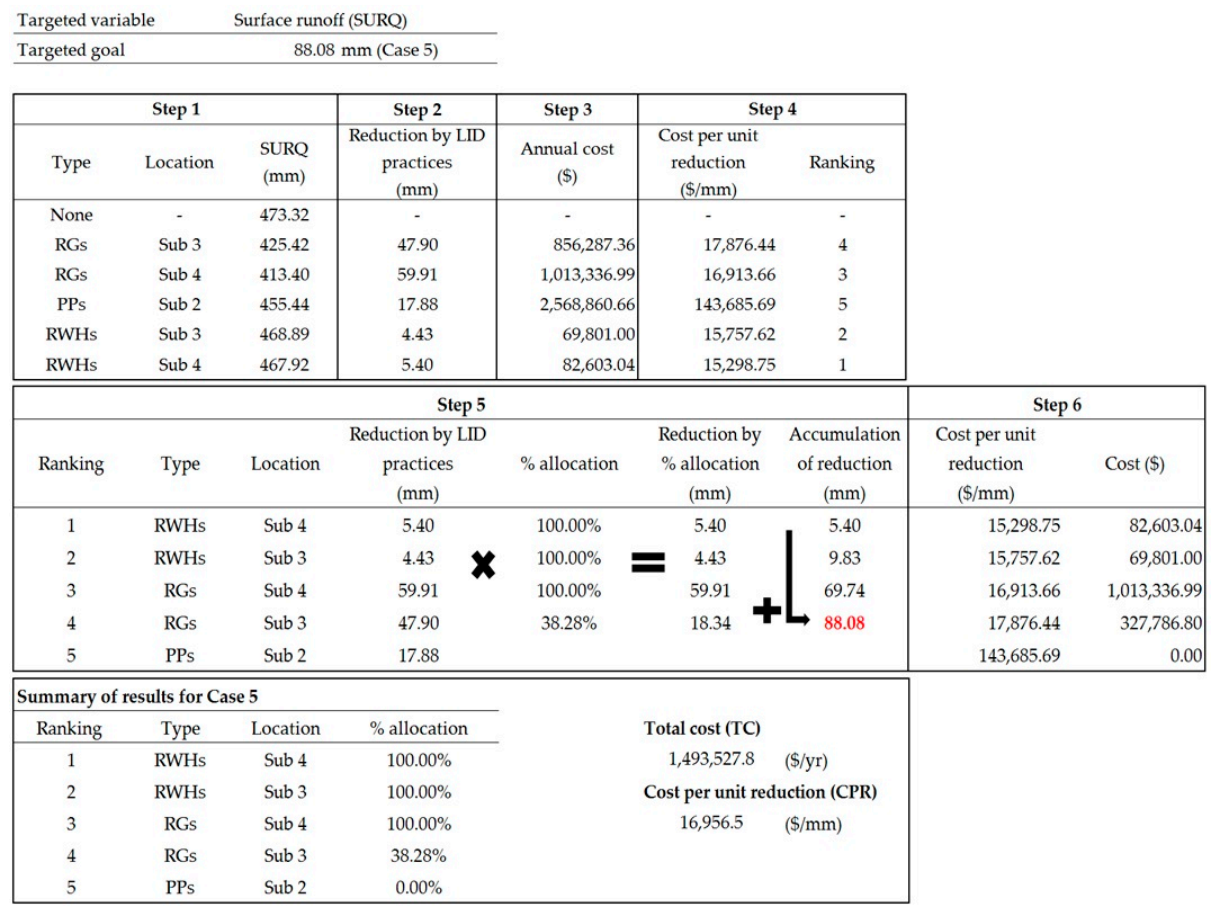

Figure A1. Example for optimization of surface runoff Case 5 under maximum adoption. A Microsoft Excel version of this table can be found in supplemental material. 


\section{References}

1. Freeman, H. The road to LID plan approval in coastal North Carolina: Development of a spreadsheet modeling tool for LID based designs. In Presented at World Environmental and Water Resources Congress, Kansas City, MO, USA, 17-21 May 2009.

2. Paul, M.J.; Meyer, J.L. Streams in the urban landscape. Annu. Revecol. Syst. 2001, 32, 333-365. [CrossRef]

3. Tong, S.T.; Chen, W. Modeling the relationship between land use and surface water quality. J. Environ. Manag. 2002, 66, 377-393. [CrossRef]

4. Newcomer, M.E.; Gurdak, J.J.; Sklar, L.S.; Nanus, L. Urban recharge beneath low impact development and effects of climate variability and change. Water Resour. Res. 2014, 50, 1716-1734. [CrossRef]

5. Dietz, M.E.; Clausen, J.C. Stormwater runoff and export changes with development in a traditional and low impact subdivision. J. Environ. Manag. 2008, 87, 560-566. [CrossRef] [PubMed]

6. Damodaram, C.; Giacomoni, M.H.; Prakash Khedun, C.; Holmes, H.; Ryan, A.; Saour, W.; Zechman, E.M. Simulation of combined best management practices and low impact development for sustainable stormwater management. J. Am. Water Resour. Assoc. 2010, 46, 907-918. [CrossRef]

7. Jeon, J.H.; Lim, K.J.; Choi, D.H.; Kim, T.D. Modeling the effects of low impact development on Runoff and Pollutant Loads from an Apartment complex. Environ. Eng. Res. 2010, 15, 167-172. [CrossRef]

8. Jeong, J.; Kannan, N.; Arnold, J.G.; Glick, R.; Gosselink, L.; Srinivasan, R.; Barrett, M.E. Modeling sedimentation-filtration basins for urban watersheds using Soil and Water Assessment Tool. J. Environ. Eng. 2013, 139, 838-848. [CrossRef]

9. Brander, K.E.; Owen, K.E.; Potter, K.W. Modeled impacts of development type on runoff volume and infiltration performance. J. Am. Water Resour. Assoc. 2004, 40, 961-969. [CrossRef]

10. Holman-Dodds, J.K.; Bradley, A.A.; Potter, K.W. Evaluation of hydrologic benefits of infiltration based urban storm water management. J. Am. Water Resour. Assoc. 2003, 39, 205-215. [CrossRef]

11. Ackerman, D.; Stein, E.D. Evaluating the effectiveness of best management practices using dynamic modeling. J. Environ. Eng. 2008, 134, 628-639. [CrossRef]

12. Carter, T.; Jackson, C.R. Vegetated roofs for stormwater management at multiple spatial scales. Landsc. Urban Plan. 2007, 80, 84-94. [CrossRef]

13. Schneider, L.E.; McCuen, R.H. Assessing the hydrologic performance of best management practices. J. Hydrol. Eng. 2006, 11, 278-281. [CrossRef]

14. Gilroy, K.L.; McCuen, R.H. Spatio-temporal effects of low impact development practices. J. Hydrol. 2009, 367, 228-236. [CrossRef]

15. Williams, E.S.; Wise, W.R. Hydrologic impacts of alternative approaches to storm water management and land development. J. Am. Water Resour. Assoc. 2006, 42, 443-455. [CrossRef]

16. Seo, M.; Jaber, F.; Srinivasan, R.; Jeong, J. Evaluating the impact of Low Impact Development (LID) practices on water quantity and quality under different development designs using SWAT. Water 2017, 9, 193. [CrossRef]

17. Endreny, T.; Collins, V. Implications of bioretention basin spatial arrangements on stormwater recharge and groundwater mounding. Ecol. Eng. 2009, 35, 670-677. [CrossRef]

18. Ahiablame, L.M.; Engel, B.A.; Chaubey, I. Effectiveness of low impact development practices in two urbanized watersheds: Retrofitting with rain barrel/cistern and porous pavement. J. Environ. Manag. 2013, 119, 151-161. [CrossRef] [PubMed]

19. Arabi, M.; Govindaraju, R.S.; Hantush, M.M. Cost-effective allocation of watershed management practices using a genetic algorithm. Water Resour. Res. 2006, 42. [CrossRef]

20. Chaubey, I.; Maringanti, C.; Schaffer, B.; Popp, J. Targeting vs. Optimization: Critical evaluation of BMP implementation plan for watershed management. In Presented at the World Environmental and Water Resources Congress 2008 Ahupua'a, Honolulu, HI, USA, 12-16 May 2008.

21. Liu, Y.; Bralts, V.F.; Engel, B.A. Evaluating the effectiveness of management practices on hydrology and water quality at watershed scale with a rainfall-runoff model. Sci. Total Environ. 2015, 511, 298-308. [CrossRef] [PubMed]

22. Gitau, M.; Veith, T.; Gburek, W. Farm-level optimization of BMP placement for cost-effective pollution reduction. Trans. ASABE 2004, 47, 1923-1931. [CrossRef] 
23. Gitau, M.W.; Veith, T.L.; Gburek, W.J.; Jarrett, A.R. Watershed level best management practice selection and placement in the Town Brook watershed, New York. J. Am. Water Resour. Assoc. 2006, 42, 1565-1581. [CrossRef]

24. Maringanti, C.; Chaubey, I.; Popp, J. Development of a multiobjective optimization tool for the selection and placement of best management practices for nonpoint source pollution control. Water Resour. Res. 2009, 45. [CrossRef]

25. Maringanti, C.; Chaubey, I.; Arabi, M.; Engel, B. Application of a multi-objective optimization method to provide least cost alternatives for NPS pollution control. Environ. Manag. 2011, 48, 448-461. [CrossRef] [PubMed]

26. Rodriguez, H.G.; Popp, J.; Maringanti, C.; Chaubey, I. Selection and placement of best management practices used to reduce water quality degradation in Lincoln Lake watershed. Water Resour. Res. 2011, 47. [CrossRef]

27. League City. Comprehensive Plan 2035 Document, Chapter 5: Land Use. Updated June 2013. Available online: http:/ /tx-leaguecity4.civicplus.com/DocumentCenter/Home/View/3560 (accessed on 7 December 2013).

28. Francos, A.; Bidoglio, G.; Galbiati, L.; Bouraoui, F.; Elorza, F.; Rekolainen, S.; Manni, K.; Granlund, K. Hydrological and water quality modelling in a medium-sized coastal basin. Phys. Chem. Earth Part B 2001, 26, 47-52. [CrossRef]

29. Lee, T.; Srinivasan, R.; Moon, J.; Omani, N. Estimation of fresh water inflow to bays from gaged and ungaged watersheds. Appl. Eng. Agric. 2011, 27, 917-923. [CrossRef]

30. Spruill, C.A.; Workman, S.R.; Taraba, J.L. Simulation of daily and monthly stream discharge from small watersheds using the SWAT model. Trans. ASABE 2000, 43, 1431-1439. [CrossRef]

31. Jeong, J.; Kannan, N.; Arnold, J.; Glick, R.; Gosselink, L.; Srinivasan, R. Development and integration of sub-hourly rainfall-runoff modeling capability within a watershed model. Water Resour. Manag. 2010, 24, 4505-4527. [CrossRef]

32. Qi, C.; Grunwald, S. GIS-based hydrologic modeling in the Sandusky watershed using SWAT. Trans. ASABE 2005, 48, 169-180. [CrossRef]

33. Bracmort, K.; Arabi, M.; Frankenberger, J.; Engel, B.; Arnold, J. Modeling long-term water quality impact of structural BMPs. Trans. ASABE 2006, 49, 367-374. [CrossRef]

34. Soil Conservation Service (SCS). National Engineering Handbook; Section 4 Hydrology, Chapters 4-10; United States Department of Agriculture: Washington, DC, USA, 1972.

35. Neitsch, S.; Arnold, J.; Kiniry, J.; Williams, J. Soil and Water Assessment Tool Theoretical Documentation Version 2009; Texas Water Resources Institute: College Station, TX, USA, 2011.

36. Williams, J. Sediment routing for agricultural watersheds. J. Am. Water Resour. Assoc. 1975, 11, $965-974$. [CrossRef]

37. McElroy, A.; Chiu, S.; Nebgen, J.; Aleti, A.; Bennett, F. Loading Functions for Assessment of Water Pollution from Nonpoint Sources; United States Environmental Protection Agency, Office of Research and Development: Washington, DC, USA, 1976.

38. Williams, J.; Hann, R. Optimal Operation of Large Agricultural Watersheds with Water Quality Restraints; Texas Water Resources Institute: College Station, TX, USA, 1978.

39. Maryland Department of the Environment (MDE). Modeling Infiltration Practices Using the TR-20 Hydrologic Program (1983); Maryland Department of the Environment: Baltimore, MD, USA, 1983.

40. Mechell, J.; Lesikar, B.J. Rainwater Harvesting: Raingardens; Texas Water Resources Institute: College Station, TX, USA, 2008; Available online: http://hdl.handle.net/1969.1/87451 (accessed on 28 July 2013).

41. Bannerman, R.T.; Considine, E. Rain Gardens: A How-to Manual for Homeowners; Wisconsin Department of Natural Resources: Madison, WI, USA, 2003.

42. North Central Texas Coucil of Government (NCTCOG). Integrated Stormwater Management Technical Manual. 2014. Available online: http://iswm.nctcog.org/technical_manual.asp (accessed on 11 April 2017).

43. Shannak, S.D.; Jaber, F.; Lesikar, B. Modeling the effect of cistern size, soil type, and irrigation scheduling on rainwater harvesting as a stormwater control measure. Water Resour. Manag. 2014, 28, 4219-4235. [CrossRef]

44. Texas Commission on Environmental Quality (TCEQ). Upper Trinity River-Dallas: Implementing TMDLs through Low Impact Development. 2015. Available online: https:/ /www.tceq.texas.gov/waterquality/ nonpoint-source/projects / upper-trinity-river-dallas-tmdl-implementation-low-impact-development (accessed on 22 February 2017). 
45. United States Environmental Protection Agency (USEPA). Preliminary Data Summary of Urban Storm Water Best Management Practices; USEPA, Office of Water: Washington, DC, USA, 1999.

46. United States Environmental Protection Agency (USEPA). Quality Criteria for Water 1986; USEPA, Office of Water Regulations and Standards: Washington, DC, USA, 1986.

47. Brown, W.; Schueler, T. The Economics of Stormwater BMPs in the Mid-Atlantic Region Prepared for Chesapeake Research Consortium; Center for Watershed Protection: Silver Spring, MD, USA, 1997.

(C) 2017 by the authors. Licensee MDPI, Basel, Switzerland. This article is an open access article distributed under the terms and conditions of the Creative Commons Attribution (CC BY) license (http:/ / creativecommons.org/licenses/by/4.0/). 